\title{
AVALIAÇÃO DAS CONDIÇÕES HIGIÊNICOS SANITÁRIAS DAS LANCHERIAS DO CAMPUS DE UMA UNIVERSIDADE EM SANTA CRUZ DO SUL/RS
}

\section{ARTIGO ORIGINAL}

ZUCHETTO, Luana ${ }^{1}$

VITIELLO, Isabel Pommerehn ${ }^{2}$

ZUCHETTO, Luana. VITIELLO, Isabel Pommerehn. Avaliação das condições higiênicos sanitárias das lancherias do campus de uma universidade em Santa Cruz do Sul/RS. Revista Científica Multidisciplinar Núcleo do Conhecimento. Ano 04, Ed. 06, Vol. 12, pp. 21-32. Junho de 2019. ISSN: 2448-0959

\section{RESUMO}

A pesquisa objetivou identificar se as lancherias localizadas no campus de uma universidade em Santa Cruz do Sul - RS apresentam condições higiênicos sanitárias que garantam alimentos seguros aos consumidores. Trata-se de um estudo transversal, de caráter observacional descritivo exploratório e de natureza quantitativa realizado em setembro de 2017 cuja amostra foi composta por nove lancherias e nove funcionários, um de cada estabelecimento, localizados no campus de uma universidade em Santa Cruz do Sul/RS. Foi utilizado para coleta de dados um checklist adaptado da RDC n 275/2002, com classificação de 3 grupos, baixo, médio e alto risco de contaminação dos alimentos. Também um questionário elaborado sobre Boas Práticas de Fabricação, no qual foram considerados como conhecedores desta ferramenta os funcionários que pontuaram de 90 a 100\% de conformidades. Conforme os percentuais apresentados, 8 lancherias apresentam a classificação de médio risco e 1 de alto risco de acordo com o percentual de itens atendidos. Dos funcionários

\footnotetext{
${ }^{1}$ Bacharela em Nutrição.

${ }^{2}$ Mestre em Engenharia de Produção, Nutricionista.
} 
apenas 1 alcançou os percentuais estabelecidos considerando-o como conhecedor das BPF. Conclui-se que as lancherias localizadas no campus de uma universidade em Santa Cruz do Sul/RS apresentam médio e alto risco de contaminação para os alimentos, representando risco para a saúde dos consumidores, pois estes alimentos são manipulados em estabelecimentos que não possuem qualidade higiênicos sanitárias suficientes para garantir a segurança alimentar dos seus usuários. Sendo assim, é necessário que melhorias sejam feitas nos estabelecimentos e que haja conscientização e principalmente formação aos trabalhadores dessa área, visto que muitas das não conformidades encontradas são resultado da falta de informação dos trabalhadores. É preciso que haja um maior envolvimento da Instituição, tanto em ações de fiscalização dos estabelecimentos, quanto no incentivo à formação profissional dos proprietários e manipuladores de alimentos, pois esta poderia disponibilizá-los diversos cursos nas mais variadas áreas da saúde, com o propósito de melhorar a qualidade dos serviços oferecidos e preservar a saúde dos consumidores.

Palavras-Chave: lancherias, boas práticas, manipuladores de alimentos.

\section{INTRODUÇÃO}

Segundo dados da Associação Brasileira das Empresas de Refeições Coletivas (ABERC, 2017) este seguimento serviu em 2009 cerca de 13,6 milhões de refeições/dia e em 2016, 17,8 milhões de refeições/dia, um aumento de 30,8\%.

Dentre os vários aspectos relativos à crescente demanda pelos serviços de refeições realizadas fora do lar, a qualidade sanitária dos produtos oferecidos é considerada questão fundamental, considerando o amplo público atendido (DAMASCENO et al., 2002; PALÚ et al., 2002; CARDOSO et al., 2005).

A normatização referente ao padrão da qualidade alimentar é realizada pelo Ministério da Saúde (MS), através da Agência Nacional de Vigilância Sanitária (ANVISA), que estabelece as Boas Práticas de Fabricação (BPF), conjunto de normas técnicas que devem ser adotadas pelas unidades produtoras de refeições, para garantir a qualidade 
sanitária dos produtos alimentícios, assunto tratado na Resolução RDC № 216, de 15 de setembro de 2004 (BRASIL, 2004). A RDC no 216/2004, que dispõe sobre Regulamento Técnico de Boas Práticas para Serviços de Alimentação, cujo objetivo é o de estabelecer procedimentos de Boas Práticas para serviços de alimentação a fim de garantir as condições higiênicos sanitárias do alimento preparado.

O fator mais importante para a implementação de padrões de qualidade em empresas produtoras e fornecedoras de refeições é o treinamento dos manipuladores, quanto ao correto uso de equipamentos de proteção individual e coletiva, evitando ferimentos aos funcionários, impedindo assim contaminação dos produtos manipulados, sanitização e higienização do ambiente, utensílios e equipamentos de trabalho.

Objetivou-se avaliar se as condições higiênicos sanitárias das lancherias localizadas no campus Santa Cruz do Sul/RS da Universidade de Santa Cruz do Sul - UNISC garantem aos consumidores alimentos seguros.

\section{DESENVOLVIMENTO}

Trata-se de um estudo transversal, de caráter observacional descritivo exploratório e de natureza quantitativa, realizado nas lancherias do campus de uma Universidade no município de Santa Cruz do Sul/RS, com aprovação do CEP no 2.199.002 e CAAE: 71993317.7.0000.5343.

Fizeram parte da pesquisa as 9 lancherias e os 9 funcionários que trabalhavam nesses locais. Participaram da pesquisa os estabelecimentos cujos proprietários aceitaram participar e assinaram a Carta de Aceite e os funcionários que assinaram o TCLE.

A coleta de dados realizou-se no mês de setembro de 2017, onde aconteceram dois encontros. No primeiro encontro foi realizado o contato com os proprietários das lancherias, definidos os dias e horários para a aplicação do checklist adaptado pelas pesquisadoras da RDC nํ2 275/2002 para Avaliação dos Serviços de Alimentação nos estabelecimentos, e, o questionário elaborado pelas pesquisadoras sobre BPF aos funcionários de cada lancheria. 
No segundo encontro ocorreu a aplicação do checklist adaptado que era composto por 69 questões objetivas, das quais 52 foram observadas pelas pesquisadoras e 17 foram perguntadas aos funcionários que trabalhavam no local. Foram avaliados os critérios: edificação e instalações, áreas de produção, equipamentos, móveis e utensílios, manipuladores, produção e transporte de alimentos, produto final e documentações.

Após a aplicação do checklist foram entregues aos funcionários o questionário sobre BPF composto de 27 questões objetivas, avaliando o conhecimento dos mesmos e se estes conhecimentos eram aplicados no dia-a-dia de trabalho. Enquanto os funcionários respondiam o questionário as pesquisadoras permaneceram presentes para esclarecer as dúvidas que surgiram.

Os dados obtidos foram tabulados no software Microsoft Office Excel 2016. O checklist foi analisado de acordo com os parâmetros utilizados na RDC no 275/2002 que classifica os estabelecimentos em 3 grupos de acordo com o percentual de itens atendidos. O Grupo 1, que atende de 76 a 100\% de conformidades, sendo este considerado de baixo risco de contaminação, Grupo 2, de 51 a 75\% de conformidades, médio risco de contaminação, e, Grupo 3 que atende de 0 a 50\% dos itens verificados, considerado de alto risco de contaminação dos alimentos. Em relação ao questionário sobre BPF, os funcionários que obtiveram de 90 a 100\% de conformidades nos itens questionados foram considerados como instruídos.

Os resultados foram obtidos através do cruzamento das respostas do checklist, onde as 69 questões foram analisadas uma a uma, comparando-as entre as 9 lancherias estudadas, e, após individualmente para que se obtivesse a porcentagem de adequação dos itens de cada estabelecimento. Da mesma forma, ocorreu a análise do questionário aplicado aos funcionários.

\section{RESULTADOS E DISCUSSÃO}

Conforme demonstrado na tabela 1, a classificação das lancherias revelou que nenhuma delas pode ser classificada no Grupo 1, indicando baixo risco para 
contaminação dos alimentos; a maioria (08) atingiu de 51 a 75\% de conformidades, classificada no Grupo 2, com médio risco para contaminação dos alimentos, e uma (01) com 0 a 50\% de conformidades (Grupo 3), com alto risco para contaminação dos alimentos. A mesma tabela demonstra também o percentual de conhecimento em BPF demonstrando que apenas 1 funcionário foi considerado como conhecedor das boas práticas de fabricação.

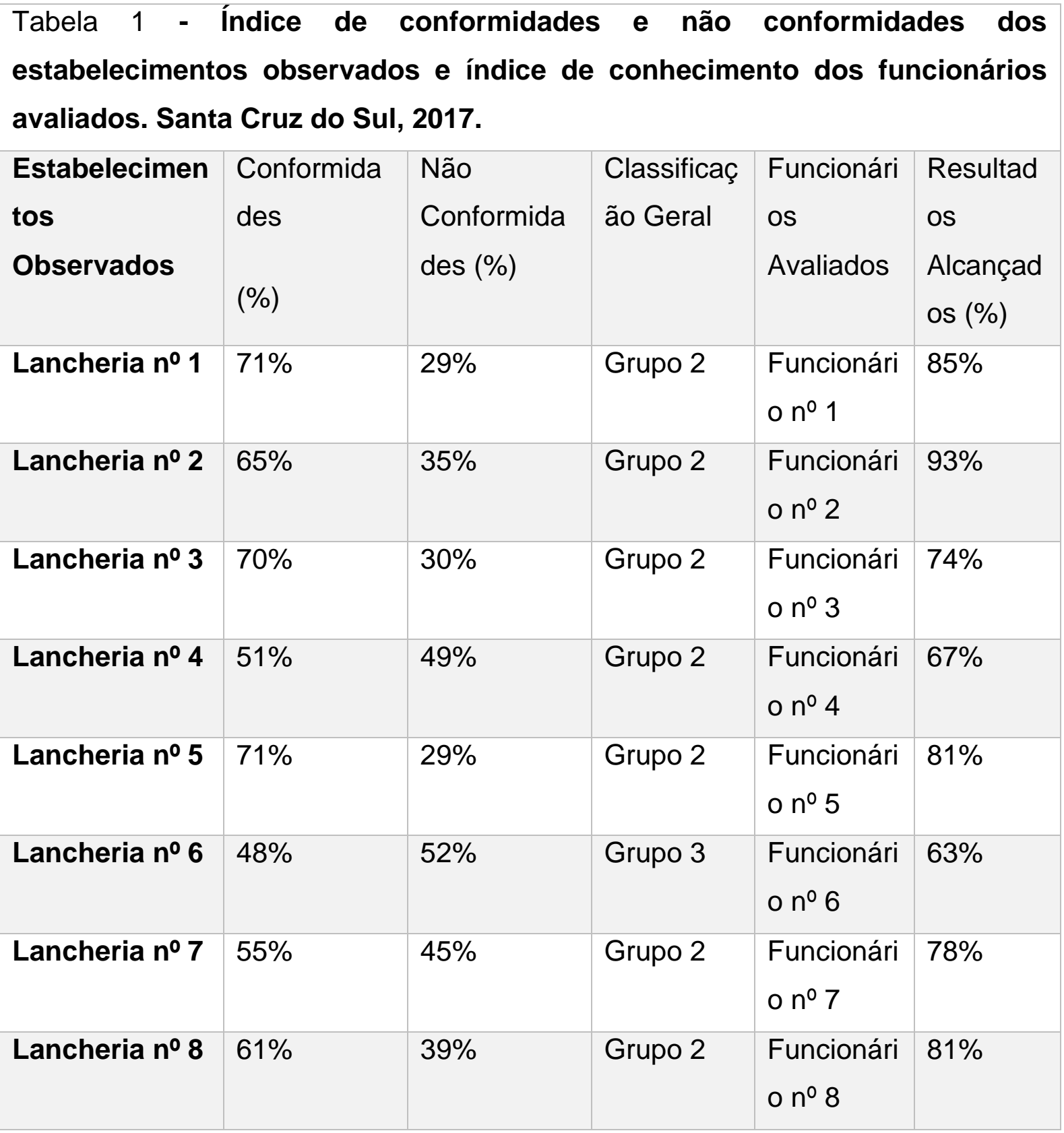




\begin{tabular}{|l|l|l|l|l|l|}
\hline Lancheria no 9 & $61 \%$ & $39 \%$ & Grupo 2 & $\begin{array}{l}\text { Funcionári } \\
\text { o no } 9\end{array}$ & $81 \%$ \\
\hline
\end{tabular}

Fonte: dados da pesquisa, 2017.

Em relação a edificações e instalações, 100\% apresentaram acesso direto à área de produção, fator considerado como sendo ideal. Quanto as não conformidades encontradas, $56 \%$ apresentavam em sua área interna objetos em desuso ou estranhos ao ambiente, $44 \%$ possuíam pisos com rachaduras, trincas ou buracos, $11 \%$ não possuíam tetos com acabamento liso, tampouco em cor clara e em razoável estado de conservação. As paredes de todas as lancherias apresentavam acabamento liso e de fácil higienização, de cor clara, porém, 22\% apresentaram falhas, rachaduras, manchas causadas por umidade ou infiltrações $e$ descascamentos. Nenhuma das 9 lancherias possuía porta externa com fechamento automático e $11 \%$ não possuíam superfície lisa dificultando a higienização. Todas as janelas com superfície lisa, de fácil higienização e ajustadas aos batentes, entretanto, $78 \%$ sem proteções contra insetos e roedores como telas milimétricas ou outro sistema que poderiam impedir a entrada destes animais nos estabelecimentos. Resultados semelhantes foram encontrados por Souza (2017), quando observou que tanto o piso e a parede da empresa alimentícia analisada não estavam em boas condições de conservação, identificando locais em que estes estavam quebrados e apresentando rachaduras em quase toda área.

Todos os estabelecimentos apresentavam iluminação adequada, sem ofuscamentos, reflexos fortes, sombras e contrastes excessivos, entretanto, 89\% das luminárias não apresentavam proteção adequada quanto a explosões, quedas acidentais e em bom estado de conservação. Nascimento e Quintão (2012) encontraram resultados semelhantes a estes em estudo que realizaram em cozinhas comunitárias, em todas a iluminação era artificial, com lâmpadas tubulares fluorescentes suficientes para as atividades realizadas, mas não possuíam proteção contra quebras. Em 100\% dos locais avaliados a ventilação e circulação de ar eram capazes de garantir o conforto térmico do ambiente, $89 \%$ destes eram climatizados artificialmente através de equipamentos com filtros adequados e higienizados periodicamente por empresas 
capacitadas, os demais possuíam equipamentos para a climatização do local, mas faziam a isto através de janelas e portas abertas sem telas milimétricas de proteção contra insetos ou roedores e através de ventiladores com acúmulo de poeira, trazendo grande risco de contaminação aos alimentos.

Quanto a higienização das instalações, somente $44 \%$ dos funcionários relataram receber orientações de como higienizar os locais, em 33\% dos estabelecimentos foram encontrados sujeira, poeira e gordura, $56 \%$ não apresentavam produtos próprios para a limpeza e higienização das instalações, desengordurantes e produtos sem perfumes regularizados pelo Ministério da Saúde. Quando existentes, em 67\% dos locais não estavam identificados e guardados em locais inapropriados, perto de utensílios utilizados na preparação dos alimentos. Nenhuma das lancherias tinha qualquer tipo de registro de higienizações realizadas ou agendadas. Resultados similares foram encontrados por Fonseca (2010) onde os problemas relacionados a higienização das instalações eram a inexistência de manipuladores capacitados e o uso de produtos de limpeza não regulamentados pelo Ministério da Saúde e armazenados em locais inadequados.

No que se refere aos vetores e pragas urbanas, não foram encontradas evidências de sua presença, como fezes, ninhos ou similares, entretanto apenas $22 \%$ dos estabelecimentos possuíam controle químico de vetores com comprovação de execução expedido por empresa especializada. Em relação ao manejo de resíduos, em $100 \%$ das lancherias os mesmos eram retirados diariamente das áreas de manipulação, e sempre que se fazia necessário, eram armazenados em local próprio para estocagem e afastado das áreas de manipulação. Entretanto, em $44 \%$ dos locais foram encontradas recipientes para coleta de lixo sem identificação, destampados ou com tampas de acionamento manual, colocando em risco a inocuidade dos alimentos manipulados. Diferentemente destes resultados foram obtidos por Reis et al (2015) que encontrou $100 \%$ de adequações em relação ao manejo de resíduos, onde todos os coletores eram equipados com tampas acionadas sem contato manual e estavam identificados, conservados e devidamente higienizados. 
O gráfico 1 mostra o número de conformidades e não conformidades encontradas nas lancherias após a aplicação do checklist adaptado da RDC № 275/2002 para Avaliação para Serviços de Alimentação.

Gráfico 1 - Total de Conformidades e Não Conformidades encontradas em cada lancheria analisada.

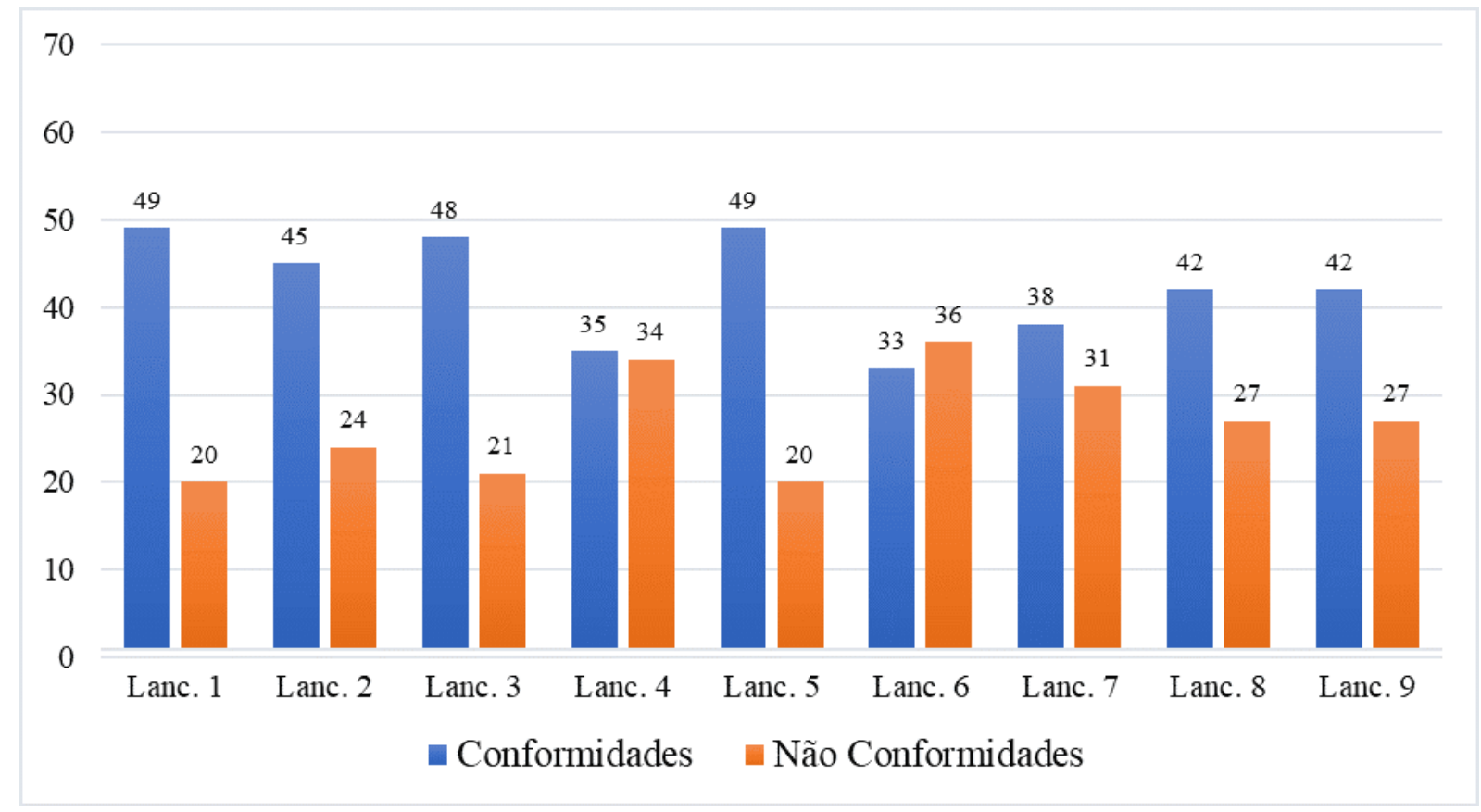

Fonte: dados da pesquisa, 2017.

Quanto aos equipamentos, móveis e utensílios disponíveis nas lancherias, 100\% dos locais apresentavam equipamentos de conservação dos alimentos (estufas, refrigeradores, congeladores, câmaras frigoríficas e outros) em adequado funcionamento, em contrapartida não existia nenhuma planilha para registro de temperaturas dos equipamentos e/ou alimentos neles armazenados. Em 22\% dos locais existiam móveis com rachaduras e frestas, de materiais inapropriados e com desenho que não permitia a fácil higienização. Os utensílios utilizados eram de material não contaminante, resistentes a corrosão e estavam armazenados em locais apropriados e protegidos contra contaminação.

Em 100\% das lancherias não eram realizadas as medições de temperatura dos itens que eram recebidos congelados ou refrigerados e não havia nenhuma planilha ou 
documento que registrava a temperatura destes. Sobre o armazenamento dos produtos $78 \%$ apresentavam inadequações quanto ao modo como estavam guardados, dispostos diretamente sobre o piso, sem o uso de paletes ou estrados, encostados nas paredes e/ou perto do teto, nas embalagens secundária (fardos de plástico ou caixas de papelão) nas quais eram transportadas até os estabelecimentos. Apenas os produtos que eram armazenados nos freezers, todos encontravam-se de acordo com a legislação, identificados com nome e data de validade visíveis, separados por tipo de produto, com embalagens intactas e acondicionados pelo prazo de validade determinado.

Os maiores índices de conformidades foram observados no item produto final, em $100 \%$ das lancherias foram encontrados produtos expostos de maneira adequada, protegidos contra insetos, poeira, materiais contaminantes e em locais sem incidência de luz solar, com dizeres de rotulagem visíveis, acondicionados em embalagens adequadas e íntegras e armazenados em locais próprios, limpos e conservados.

Quanto a documentações, nenhum dos estabelecimentos possuía Manual de Boas Práticas de Fabricação, elaborados especificamente para cada local.

A respeito dos manipuladores, dos 14 itens analisados no checklist, foram identificadas não conformidades em 12 deles, sendo que 89\% dos funcionários vestiam uniformes de cores escuras e 11\% não utilizavam calças compridas e/ou sapatos fechados, próprios para o ambiente. Quanto ao asseio pessoal, 100\% dos funcionários observados faziam uso de adornos (anéis, alianças, pulseiras, brincos, colares, piercing) ou utilizavam unhas compridas e/ou com o uso de esmaltes ou utilizavam maquiagem ou estavam com os cabelos desprotegidos. Os mesmos $89 \%$ não utilizavam toucas cobrindo totalmente os cabelos, apenas redes em parte deles. Em $67 \%$ dos estabelecimentos não haviam cartazes com orientações sobre a correta lavagem e higienização das mãos e em $89 \%$ não havia qualquer registro de capacitações dos trabalhadores. Todos os funcionários manipulavam dinheiro e alimentos simultaneamente sem a lavagem correta das mãos, 89\% conversavam durante a manipulação dos alimentos, $44 \%$ dos funcionários afirmaram ter 
equipamentos de proteção individual, mas apenas $33 \%$ fazem uso destes equipamentos.

Quando comparados os dados do checklist e os do questionário sobre BPF, identificaram-se divergências entre as respostas dos funcionários e as observações das pesquisadoras: $100 \%$ relataram utilizar sapatos fechados e adequados ao ambiente, $78 \%$ declararam manter as unhas curtas e sem esmaltes, $56 \%$ disseram manter os cabelos totalmente presos e protegidos por toucas, $67 \%$ disseram que evitam alimentar-se ou mascar chicletes durante o trabalho e 44\% relataram não usar adornos. Quanto a manipulação de dinheiro, 100\% dos funcionários declararam que manipulavam alimentos e dinheiro ao mesmo tempo, porém, em nenhuma das lancherias analisadas havia um profissional que fizesse exclusivamente o manuseio de dinheiro ou cartões. Nonato et al (2012) obteve resultados idênticos a este, onde $100 \%$ dos trabalhadores manipulavam alimentos e dinheiro simultaneamente.

O gráfico 2 mostra a porcentual de adequações encontradas em cada lancheria após análise do checklist e o percentual de conhecimento de seus respectivos funcionários em relação às boas práticas de fabricação após análise do questionário.

Gráfico 2 - Percentual de Adequações encontradas nas lancherias estudadas e Percentual de Conhecimento em BPF obtidos pelos funcionários de cada lancheria.

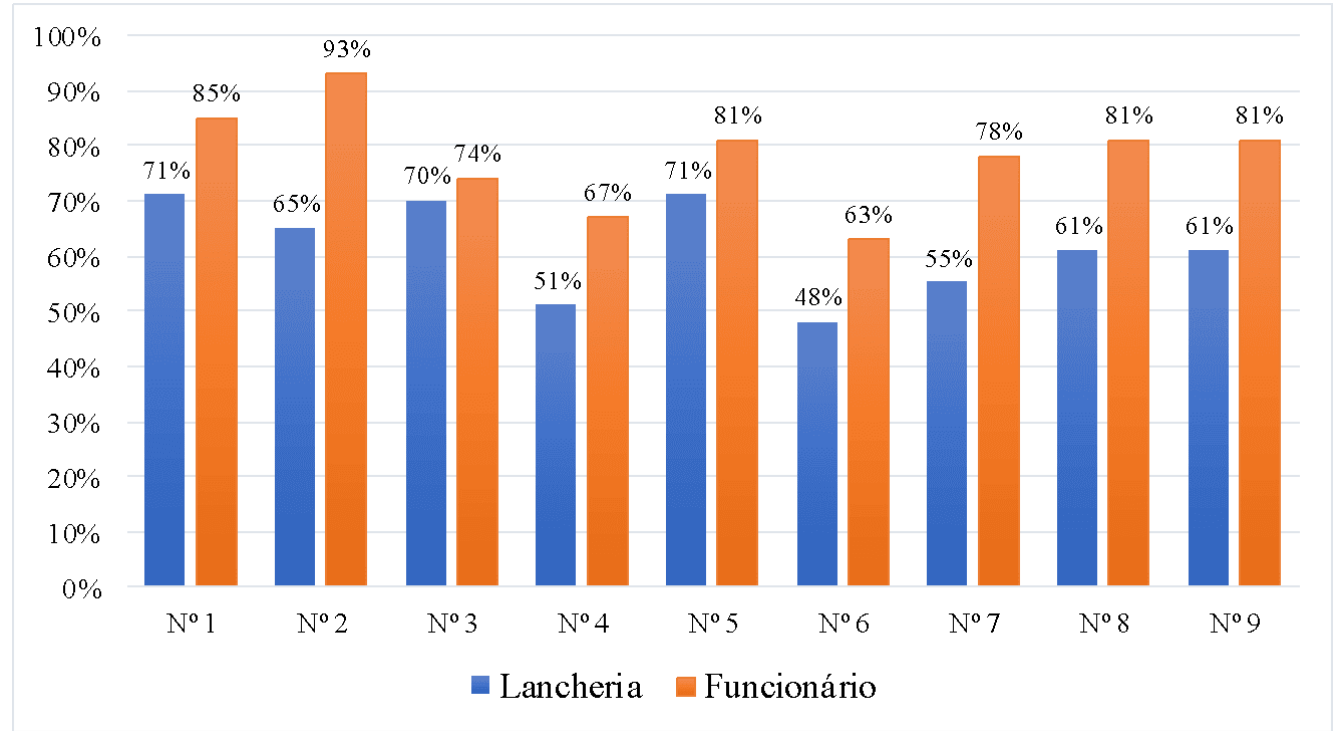


Fonte: dados da pesquisa, 2017.

Nas respostas obtidas no questionário, $67 \%$ dos funcionários responderam que não participam ou participaram de cursos ou programas relacionados a manipulação de alimentos, mas $100 \%$ deles afirmam que receberam orientações dos contratantes quanto à higiene pessoal para manipuladores de alimentos, $89 \%$ declararam ter recebido orientações sobre a correta lavagem e higienização das mãos, porém apenas 44\% utilizam sabonete líquido inodoro e anti-séptico para lavar as mãos e 56\% secam as mãos utilizando papel toalha não reciclado e descartável. Cintra et al (2017) encontrou $100 \%$ de inadequações quando verificou a lavagem das mãos dos comerciários avaliados, onde 14,28\% lavavam as mãos apenas com água, 28,57\% lavavam as mãos com detergente utilizado para lavar louças, mas posteriormente aplicavam álcool gel, e 57,14\% não lavavam as mãos.

Todos os funcionários afirmam que lavam cuidadosamente as mãos depois do uso de artigos de faxina ou produtos químicos, quando interrompem uma atividade, antes de recomeçá-la, e depois de utilizar os sanitários e/ou manipular lixos, trocam o uniforme sempre que necessário por outro limpo, e fazem uso do mesmo somente na área de trabalho, declararam não utilizar perfumes fortes durante o trabalho e afastavam-se dos alimentos ao tossir e espirrar. 100\% dizem ter consciência de que os alimentos podem transmitir doenças e podem até causar a morte e por isso preocupam-se com a qualidade dos alimentos que estão sendo manuseados.

\section{CONCLUSÃO}

De acordo com os resultados obtidos, o presente estudo concluiu que as lancherias localizadas no campus de uma Universidade em Santa Cruz do Sul/RS apresentam médio e alto risco de contaminação para os alimentos, representando risco para a saúde dos consumidores, pois estes alimentos são manipulados em estabelecimentos que não possuem qualidade higiênicossanitárias suficientes para garantir a segurança alimentar dos seus usuários. Sendo assim, é necessário que melhorias sejam feitas nos estabelecimentos e que haja conscientização e principalmente formação aos 
trabalhadores dessa área, visto que muitas das não conformidades encontradas são resultado da falta de informação dos trabalhadores.

É preciso que haja um maior envolvimento da Instituição, tanto em ações de fiscalização dos estabelecimentos, quanto no incentivo à formação profissional dos proprietários e manipuladores de alimentos, pois esta poderia disponibilizá-los diversos cursos nas mais variadas áreas da saúde, com o propósito de melhorar a qualidade dos serviços oferecidos e preservar a saúde dos consumidores.

\section{REFERÊNCIAS}

ABERC - Associação Brasileira de Empresas de Refeições Coletivas. [on line]. Disponível em: <http://www.aberc.com.br/mercadoreal.asp?IDMenu=21>. Acesso em 10 out. 2017.

BRASIL. Agência Nacional De Vigilância Sanitária - ANVISA. Resolução RDC 275 de 21 de outubro de 2002. Dispõe sobre o regulamento técnico de Procedimentos Operacionais Padronizados aplicados aos estabelecimentos produtores/industrializadores de alimentos e a lista de verificação das boas práticas de fabricação em estabelecimentos produtores/industrializadores de alimentos. Diário Oficial da União, Brasília, 06 de novembro de 2002. Disponível em: <http://www.rio.rj.gov.br/dlstatic/10112/5125403/4132350/ResoluuoRDC27521.10.20 02.pdf>. Acesso em: 11 out. 2017.

CARDOSO, R.C.V.; SOUZA, E.V.A.; SANTOS, P.Q. Unidades de alimentação e nutrição nos campi da Universidade Federal da Bahia: um estudo sob a perspectiva do alimento seguro. Revista de Nutrição, Campinas, v. 18, n. 5, p. 669-680, set./out. 2005. Disponível em: <http://www.scielo.br/scielo.php?script=sci_arttext\&pid=S1415$52732005000500010>$. Acesso em 02 nov. 2017.

CINTRA, P.; GÓIS, E.M.; BRUNHARO, M.S.M.; MOREIRA, D.O.S. Boas práticas de manipulação no comércio ambulante de alimentos em campus universitário da Grande Dourados, MS. Revista Higiene Alimentar, São Paulo, v.31, n.266/267, p. 27-30, 2017. 
DAMASCENO, K.S.F.S.C. et al. Condições higiênico-sanitárias de "self-services" do entorno da UFPE e das saladas cruas por elas servidas. Revista Higiene Alimentar, São Paulo, v. 16, n. 102/103, p. 74-80, 2002.

FONSECA, M.P.; MANFRIDINI, L.A.; SÃO JOSÉ, J.F.B.; TOMAZINI, A.P.B.; MARTINI, H.S.D.; RIBEIRO, R.C.L.; SANT'ANA, H.M.P. Avaliação das condições físico-funcionais de restaurantes comerciais para implementação das boas práticas. Revista Alimentos e Nutrição, Araraquara, v.21, n.2, p 251-257, abr/jun 2010. Disponível https://s3.amazonaws.com/academia.edu.documents/43546666/AVALIAO_DAS_CO NDIES_FSICO-FUNCIONAIS_DE_20160309-7346inf4gi.pdf?AWSAccessKeyld=AKIAIWOWYYGZ2Y53UL3A\&Expires $=1511842080 \& S i$ gnature=D3\%2FOTBGNQ7ydJTgu9QSOQRGpVmY\%3D\&response-contentdisposition=inline\%3B\%20filename\%3DAvaliacao_Das_Condicoes_FisicoFuncionai.pdf> Acesso em: 23 nov 2017.

NASCIMENTO, J.C.; QUINTÃO, D.F. Avaliação das condições de ambiência em três cozinhas comunitárias do município de Leopoldina (MG). Revista Científica da Faminas, v.8, n.1, jan/abr 2012. Disponível em: $<$ http://periodicos.faminas.edu.br/index.php/RCFaminas/article/view/286> Acesso em: 22 nov 2017.

NONATO IL, FONSECA VRS, PAZ JG, NOMELINI QSS, PASCOAL GB, SOUZA DAD. Qualidade higiênico sanitária de pontos de venda e análise microbiológica de alimentos de rua comercializados no campus Umuarama da universidade federal de Uberlândia. Biosci J, Uberlândia, v.28, n.6, p.1061-1071, nov/dez 2012. Disponível em:

$<$ https://www.researchgate.net/profile/DA_De_Souza/publication/258520185_Sanitar $y-$

hygienic_quality_of_sale_points_and_microbiological_analysis_of_street_food_sold_ in_the_umuarama_campus_of_the_federal_university_of_uberlandia/links/00b7d528 94ae182ca6000000/Sanitary-hygienic-quality-of-sale-points-and-microbiological- 
analysis-of-street-food-sold-in-the-umuarama-campus-of-the-federal-university-ofuberlandia.pdf> Acesso em: 27 nov 2017.

PALÚ, A.P. et al. Avaliação microbiológica de frutas e hortaliças frescas, servidas em restaurantes self-service privados da Universidade Federal do Rio de Janeiro. Revista Higiene Alimentar, São Paulo, v. 16, n. 100, p. 67-74, 2002.

POERNER, N.; RODRIGUES, E.; PALHANO, A.L.; FIORENTINI, A.M. Avaliação das condições higiênico-sanitárias em serviços de alimentação. Revista Instituto Adolfo Lutz, São Paulo, v.68, n.3, p. 399-405, 2009. Disponível em: <http://periodicos.ses.sp.bvs.br/pdf/rial/v68n3/v68n3a11.pdf> Acesso em: 23 nov 2017.

REIS, H.F.; FLÁVIO, E.F.; GUIMARÃES, R.S.P. avaliação das condições higiênicosanitárias de uma unidade de alimentação e nutrição hospitalar de Montes Claros, MG. Revista Unimontes Científica, Montes Claros, v.17, n.2, ago/dez 2015. Disponível em: $<$ http://www.ruc.unimontes.br/index.php/unicientifica/article/view/369/343> Acesso em: 22 nov 2017.

SOUZA, et al. Avaliação das boas práticas de manipulação em serviços de alimentação e nutrição localizados na cidade de Maceió, AL. Revista Higiene Alimentar, São Paulo, v.31, n.270/271, p. 45-49, jul/ago 2017.

Aprovado: Agosto, 2018.

Enviado: Junho, 2019. 